\title{
Literature Review on Leadership in Healthcare Management
}

\author{
Rashmi Chatterjee \\ School of Public Affairs, University of Science and Technology of China, \\ Hefei, Anhui, 230026, China \\ Tel: +86-15695699205 E-mail: rashmi@mail.ustc.edu.cn
}

Rathny Suy

School of Public Affairs, University of Science and Technology of China, Hefei, Anhui, 230026, China

Tel: +86-18755182753 E-mail: rathny@mail.ustc.edu.cn

Yat Yen

School of Public Affairs, University of Science and Technology of China, Hefei, Anhui, 230026, China

Tel: +86-15665422787 E-mail: yy2014@mail.ustc.edu.cn

Leaksmy Chhay

School of Management, University of Science and Technology of China, Hefei, Anhui, 230026, China

Tel: +86-1515093101Ｅ-mail: leaksmy@mail.ustc.edu.cn

Received: May 22, 2017 Accepted: June 26, 2017 Published: June 28, 2017

doi: 10.5296/jsss.v5i1.11460 URL: http://doi.org/10.5296/jsss.v5i1.11460 


\begin{abstract}
Health care organization is a complicated network of numerous professional groups, departments and specialists. A change is needed in order to enhance the service quality as well as the organizational performance in the health care system. However, it is difficult for most of the health care organizations to innovate; specifically in terms of managerial system and culture. A leader can act as a catalyst for achieving the effective change to remain successful in an ever changing, competitive environment. A crucial leadership gap exists in the current health care system. Numerous theories, cases, and models have influenced the current leadership strategies that can be connected to the healthcare setting. This review provides the impact of different leadership styles in organizational performances in health care management.
\end{abstract}

Keywords: Health care organization, Health care management, Leadership, Organizational performance, Service improvement

\title{
1. Introduction
}

Theories of leadership have not been developed within the health care settings but were created in the business context and applied to the health care unit. So, the theories are dynamic in nature and will transform over the period of time. Health care organizations are comprised of complex interfaces among large number of professionals with numerous roles. The unique structure of health care organizations usually follows the traditional or past practices that can resist changing (Kumar et al., 2015). According to Bossidy and Charan (2002), effective cooperation is a critical shortfall in many health care arenas. So, the effective leadership is crucial to bring necessary changes for quality improvement of the organizations.

For some people the terms management and leadership are similar. According to Peter Drucker, leadership is doing the right things whereas management is doing things right. Management strongly focuses on status qua but leadership encourages innovative thinking, change for the future of the organization (Manion, 2005). Now days, health care industry is increasingly competitive with the changing environment and the leadership become the pillar for motivating and inspiring change for future (Kotter, 2003).

Leadership exists inside connections that are accessible to all through an organization. It is just an art of motivating people so that they will try enthusiastically to achieve group goals. This can significantly emphasize on collaboration within organizations so that the leaders and followers can raise each other motivational level and cherishes interdependencies among multiple stakeholders (VanVactor, 2012). Leadership has been depicted as the conduct of a person while coordinating the activities towards a common objective and adapting to change (Al-Sawai, 2013).According to Hartley and Benington (2010) leadership should be developed as an intricate set of practices by many people within specific organizational and inter organizational cultures.

Health care management should be collaborated with multifaceted groups to work together such that it can support future goal of reducing illness and improving the health status of the 
community (VanVactor, 2015). Every manager within health care settings can integrate collaborative communication strategies which can extend beyond traditional organizational boundaries (VanVactor, 2015). Leadership positions in healthcare are often regarded as a highly specialized subset of the broader management areas and many of the broader debates about management education (Andrew, 2010). Healthcare leaders, who are spiritually more developed can significantly achieve more positive results for their organization by challenging the process, shared vision and motivating others to work in a classical way (Gary et al., 2002). The Healthcare Leadership Alliance (HLA), is a unique model for individuals and organizations. This can be utilized for foster association and development across the broad range of healthcare management unit (Stefl et al., 2008). Wikstro“m and Dellve (2009) have dealt with cotemporary challenges for health care leaders. They proposed two models for describing and distinguishing ways of achieving different needs in health sector. The first model described as leadership by separating different logics and fragmentation by managing challenges within separate rooms. The second model described integrating different logics and reediness of solution by managing different challenges at the same time.

The key element of this study is to determine the influences of the leadership in healthcare management. The focal points are - the theories of leadership, collaborative leadership, distributive leadership and leadership model in the management of health care to improve the quality.

\section{Literature Review}

\subsection{Definitions of Leadership}

Warren Bennis, a pioneer of leadership studies, described leadership as 'a function of knowing yourself, having a vision that is well communicated, building trust among colleagues, and taking effective action to realize your own leadership potential' (Kumar \& Khiljee, 2015). According to Peter Drucker a leader is someone who has his own followers. Kouzes and Posner reported that 'Leadership can happen at anytime, anywhere and in any function'. They also mentioned certain behavior which leader exhibits in their life.

\subsection{Theories of Leadership}

D C Kumar and Noshaba Khiljee (2015) specified six theories to address what supports fruitful leadership; the six theories are:

- Great Man theory: It is an early outdated theory that suggests leaders are born, not made. They lead through their personal attributes, such as charisma, intelligence and wisdom.

- Trait theory: This theory was developed in the early 20th century. It has some similarities with the Great Man theory. It states that some people possess certain traits that cannot be learnt (e.g. adaptability, ambitiousness, assertiveness) and are particularly suitable in a number of different situations.

- Behavioral theory: In 1960s the focus of leadership theory shifted to behavioral theory from trait theory (i.e. what leaders actually do). The behaviors of successful leadership styles can be distinguished from those that are ineffective. 
- Contingency theory: According to this theory effective leaders develop unique ways of working with their followers depending on the situation and the needs and attributes of followers.

- Transactional leadership: This is similar to dictatorial leadership. Leaders identify what needs to be done to achieve goals, including clarifying roles, tasks, rewarding the performance of the followers.

- Transformational leadership: This states that people will take a leader who inspires them through vision, passion and enthusiasm.

The emphasis on transformational (and value-based) initiative was likewise recognized in an orderly survey performed by Gilmartin and D'Aunno (2007) looking at medicinal services initiative research from 1989 to 2005 . They presumed that reviews in social insurance give strong support to transformational leadership theory and distinguished connections with staff fulfillment, unit or group execution, hierarchical atmosphere and turnover aims (M.J. \& Thomas, 2007). The impacts are more grounded when evaluated among additional junior than high ranking staff. Valuable outcomes of transformational leadership have been shown in connection to work-life adjust, staff prosperity, positive nursing results, tolerant security, openness about blunders, and patient and staff fulfillment (Aiken et al., 2011; Kvist et al., 2013; Munir, Nielsen, Garde, Albertsen, \& Carneiro, 2012; Wong \& Giallonardo, 2013).

\section{Method}

This study used a descriptive design, by exploring some of the literature that discussed about the different leadership styles and leadership models used in management of healthcare to improve the quality in this sector.

\section{Discussion}

\subsection{Collaborative Leadership}

Collaboration is a skill that helps individuals and teams to operate in a more effective way. It is a mutual relationship with clearly defined roles within multiple stakeholders for accomplishment of a common organizational goal (Atchison \& Bujak, 2001). Collective leadership helps to communicate information to colleagues and related associations that allow them to make their own decision. Such collaborative environment upgrades healthcare management by empowering multiple stakeholders, sharing knowledge and experiences and diminishing the level of intricacy inside healthcare organizations (Al-Sawai, 2013, Chen \& Silverthorne, 2005, Ewan et al., 2005). Collaboration helps in strengthening interpersonal relationship which creates an environment of trust that nurture diverse skill sets for creative problem solving (Uzzi \& Dunlap, 2005). Collaborative healthcare leadership requires a synergistic work condition, where multiple stakeholders are working toward execution of best practices. Such collaborations encourage the conception of various cultures and facilitate integration and interdependency among multiple parties (JO, 2005; Thomas \& Joseph, 2001), where individuals are influenced by shared values and resulting synergistic working practices where the outcomes are greater than sum of individual efforts (Al-Sawai, 2013). 


\section{Macrothink}

\subsection{Distributive Leadership}

The goal of distributive leadership is to create an environment where individuals can complement each other's strengths and the weakness throughout the organization. This type of leadership is considered as less hierarchical and more collaborative in nature (Al-Sawai, 2013). Distributive leader possesses interdependent characteristics of sense making, relating, visioning \& inventing. As healthcare organizations are going through a changing phase, therefore distributive leadership can help to understand the effect of change and create an atmosphere of trust where employees have freedom to innovate ideas for the attainment of the organizational goal.

\subsection{Shared Leadership}

Shared leadership is built on delegation of task and collaborative relationships through the support from all employees as in the healthcare settings (Al-Sawai, 2013). It promotes share governance, continuous learning and builds strong work relationships. The key factor of this approach is team work with specified team values. In this leadership, all the staffs are involved in decision making process.

\subsection{The Model of Collaborative Leadership}

In order to understand the effectiveness of the separate elements, collaborative leadership must be a local component in the outline of management procedures .Communicating collaboratively should turn into a never-ending cycle among numerous partners to guarantee correspondence channels remain unobstructed (VanVactor, 2012). Managers will incorporate change frequently for the accomplishment of organizational goal (Kim, Gaukler, \& Lee, 2016). Leaders can capitalize from this instance and use the assets that would conventionally go unused through an organization. Multiple stakeholders involved in a health care environment form a collection of beneficiaries to an efficient collaborative leadership environment (see Figure 1). 


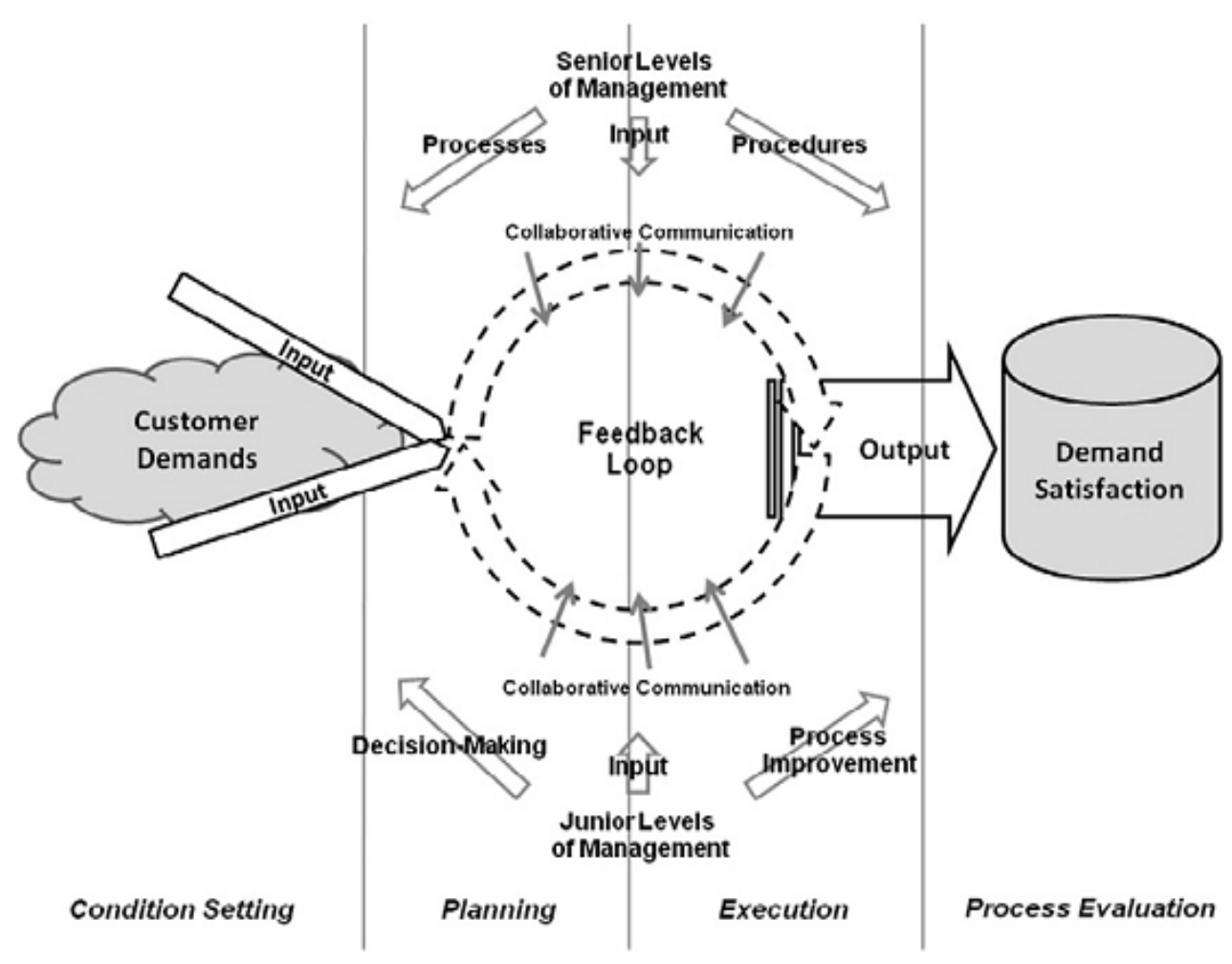

Figure 1. Collaborative communications leadership model

Source: VanVactor, J.D, 2010 \& 2012.

Leaders must be cognizant of how to introduce information into health care processes (condition setting phase). Managers at different level make decisions about how people's need should be met throughout an organization (planning phase). Through this dynamic process, data enters in a feedback loop where the data processed and select the best and productive technique for satisfying demands (execution phase). Procedural direction is conveyed by senior leaders and specific results are assessed by junior leaders yielding a potential for process change for future (evaluation phase) (VanVactor, 2012). The main element of this model is the feedback loop. Success or failure in the result of this procedure is dependent on the process of data exchange. Effective collaborative procedures upgrade health care management through open communication among multiple stakeholders. Collaboration includes multiple stakeholders making a perpetual dialogue, feedback loop to maintain an alliance properly aligned among multiple stakeholders. For the speed \& efficiency, healthcare leaders often move from team approach to problem solution and minimize interaction among subordinates or external stakeholders (Meredith, 2009). One part of managing organizations cooperatively is teaching employees the standards related to an educated hierarchical culture where promptly shared data exists among multiple leaders and employees. While many would debate the role of the manager in an organization is to fill in as the information monitor, disseminator, and representative (Longest, Rakich, \& Darr, 2000), sharing this role equilaterally among different role all through an organization is perfect. 


\section{Macrothink Institute ${ }^{T M}$}

By inculcating an organizational culture in light of effective information and knowledge sharing, stakeholders make aware the management of risks and give suggestions relating to the welfare of an organization. Sometimes, issues overlooked by various levels of management may bear significant impacts of existing business operations and patient safety. Collaborative communication can serve as a significant contributor in the minimization of organizational risk; intra- and interdepartmental communications may encourage change that is necessary in order to handle situations which are risk producing (VanVactor, 2012).

\subsection{The Model of Distributive Leadership}

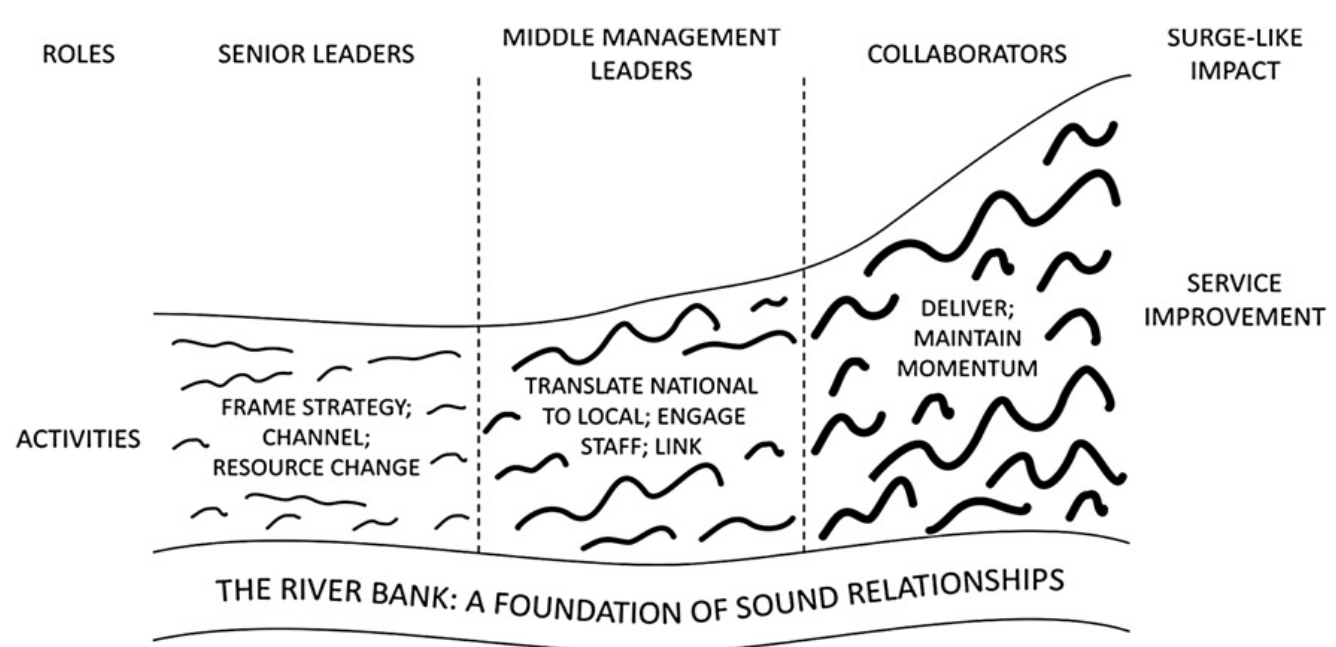

Figure 2. Impact of distributive leadership on service improvement

Source: L. Fitzgerald et al. 2012.

This model reveals that broadly distributed change of leadership positively influenced the service quality in the health care context. From the model, it is observed that the effectiveness of a multi staged distributed leadership is strengthened by good interpersonal relationships. The gaps in the distribution of leadership reduce the progress in service improvement (Fitzgerald et al., 2012). Distributed leadership in healthcare (multi professional organization) consists of three elements that spread across senior, middle and lower level of organization (Currie \& Lockett, 2011). Diagram depicts that changes are ordered and consecutive process. According to Denis et al. (2001) if leaders are present in the top level then service delivery may become inefficient. Health Care organization is enriched with skills and knowledge of multiple parties that enhance the cumulative effect of service improvement. The ability of distributed leadership to deliver change may be a function of different contextual conditions, such as consistent communication of strategic priorities or may be hindered by negative features, such as a lack of autonomy (Fitzgerald et al., 2012).

Distributed leadership facilitates co-ordination across the organization which is very essential in a multi-disciplinary organization. The overall capacity of distributed leadership is 
enhanced by variable combinations of roles, relationships and contexts to deliver similar outcomes.

\section{Conclusion}

Leadership is an association of science and an art. It exists inside connections and encouraging a collaborative environment that promotes innovative thinking and interdependency among numerous stakeholders within an organization. Different leadership approaches can be adopted to the health care setting to optimize management in this highly complex environment. According to Schneller and Smeltzer (2006), no one leadership style is appropriate for effective management of health care assets and resources. Leaders should give attention to the dynamic connections between leadership values, culture, abilities and the organizational context. In healthcare management synergistic relationship should be understood by the leaders. Leaders have to identify the cultural differences that exists between different functional groups and this differences needs to be appreciated (Langer, 2015). Collaborative leadership is a type of transformation leadership, which is not frequently utilized inside a health care setting. With the help of collaborative and distributive leadership everybody empowered with responsibility for organizational success. Quality improvement initiative will be successful when healthcare professionals feel they have ownership of the task. Leadership development has already reached to a standard and the most essential part of the leadership is to promote change in the continually evolving healthcare environment.

\section{Acknowledgement}

Rashmi Chatterjee acknowledged CAS-TWAS Presidents' Fellowship for financial support.

\section{References}

Aiken, L. H., Sloane, D. M., Clarke, S., Poghosyan, L., Cho, E., You, L., \& Aungsuroch, Y. (2011). Importance of Work Environments on Hospital Outcomes in Nine Countries. International Journal for Quality in Health Care, 23(4), 357-364. https://doi.org/10.1093/intqhe/mzr022

Al-Sawai, A. (2013). Leadership of healthcare professionals: where do we stand? Oman medical journal, 28(4), 285-287. https://doi.org/10.5001/omj.2013.79

Atchison, T. A., \& Bujak, J. S. (2001). Leading transformational change: the physician-executive partnership. Chicago: Health Administration Press.

Andrew, G. (2010). Healthcare Leadership 'Outliers': An Analysis of Senior Administrators from the Top U.S. Hospitals. Journal of Health Administration Education, 27(2), 87-98.

Bossidy, L., \& Charan, R. (2002). Execution: the discipline of getting things done. New York: Crown Business.

Chen, J. C., \& Silverthorne, C. (2005). Leadership effectiveness, leadership style and employee readiness. Leadership \& Organization Development Journal, 26(4), 280-288. https://doi.org/10.1108/01437730510600652 


\section{Macrothink}

Journal of Social Science Studies

ISSN 2329-9150 2018, Vol. 5, No. 1

Collins, D. B., \& Holton, E. F. (2004). The effectiveness of managerial leadership development programs: A meta-analysis of studies from 1982 to 2001. Human Resource Development Quarterly, 15(2), 217-248. https://doi.org/10.1002/hrdq.1099

Currie, G., \& Lockett, A. (2011). Distributing leadership in health and social care: Concertive, conjoint or collective? International Journal of Management Reviews, 13(3), 286-300. https://doi.org/10.1111/j.1468-2370.2011.00308.x

Denis, J. -L., Lamothe, L., \& Langley, A. (2001). The dynamics of collective leadership and strategic change in pluralistic organizations. Academy of Management Journal, 44(4), 809-837. https://doi.org/10.2307/3069417

Ewan, F., Karen, G.-B., Jean-Louis, D., D, D., John, L., \& Andy, O. (2005). Towards systematic reviews that inform health care management and policy-making. Journal of Health Services Research \& Policy, 35-48.

Hartley, J., \& Benington, J. (2010). Leadership for healthcare. Policy press at the University of Bristol. https://doi.org/10.1332/policypress/9781847424877.001.0001

JO, M. (2005). From Management to Leadership Practical Strategies for Health Care Leaders (2nd ed.). San Francisco: Jossey-Bass Inc Pub.

Kim, R. H., Gaukler, G. M., \& Lee, C. W. (2016). Improving healthcare quality: A technological and managerial innovation perspective. Technological Forecasting and Social Change, 113, Part B. https://doi.org/10.1016/j.techfore.2016.09.012

Kotter, J. P. (2003). What leaders really do. Business leadership. San Francisco.

Kvist, T., MÄntynen, R., Turunen, H., Partanen, P., Miettinen, M., Wolf, G. A., \& VehvilÄInen-Julkunen, K. (2013). How magnetic are Finnish hospitals measured by transformational leadership and empirical quality outcomes? Journal of Nursing Management, 21(1), 152-164. https://doi.org/10.1111/j.1365-2834.2012.01456.x

Langer, L. J. (2015). Leadership Strategies for Biotechnology Organizations: A Literature Review. Biennial Review of Health Care Management: Meso Perspectives Advances in Health Care Management, 8, 49-80. https://doi.org/10.1108/S1474-8231(2009)0000008007

Longest, B., Rakich, J., \& Darr, K. (2000). Managing health services organizations and systems (4th ed.). Baltimore: Health Professions Press.

Manion J. (2005). From management to leadership: practical strategies for healthcare leaders. (2nd ed.) San Francisco: Jossey-Bass.

M. J., G., \& Thomas, D. A. (2007). Leadership research in healthcare: A review and roadmap. Academy of Management Annals, 1(1), 387-438. https://doi.org/10.1080/078559813

Meredith, J. R. (2009). Issues in the modeling-empiricism gap. Supply Chain Management, 45(1), 44-48. https://doi.org/10.1111/j.1745-493X.2009.03155.x

Munir, F., Nielsen, K., Garde, A. H., Albertsen, K., \& Carneiro, I. G. (2012). Mediating the 


\section{Macrothink}

Journal of Social Science Studies

ISSN 2329-9150

2018, Vol. 5, No. 1

effects of work-life conflict between transformational leadership and health-care workers' job satisfaction and psychological wellbeing. Journal of Nursing Management, 20(4), 512-521. https://doi.org/10.1111/j.1365-2834.2011.01308.x

Robin, D. K., \& Noshaba, K. (2015). Leadership in healthcare. Anaesthesia and intensive care medicine, 17(1), 63-65.

Schneller, E. S., \& Smeltzer, L. R. (2006). Strategic management of the healthcare supply chain. San Francisco: John Wiley \& Sons, Inc.

Stefl, M. E., \& Bontempo, C. A. (2008). Common competencies for all healthcare managers: the healthcare leadership alliance model. Journal of Healthcare Management.

Strack, G., \& Fottler, M. D. (2002). Spirituality and effective leadership in healthcare: is there a connection? Journal of Frontiers of Health Services Management, 18(4), 3-18.

Thomas A., A., \& Joseph S., B. (2001). Leading transformational change: the physician executive partnership. Chicago: Health Administration Press.

Uzzi, B., \& Dunlap, S. (2005). How to build your network. Harv Bus Rev, 83(12), 53-60.

VanVactor, J. D. (2012). Collaborative leadership model in the management of health care. Journal of Business Research, 65(4), 555-561. https://doi.org/10.1016/j.jbusres.2011.02.021

Wikstro"m, E., \& Dellve, L. (2009). Contemporary leadership in healthcare organizations Fragmented or concurrent leadership. Journal of Health, Organization and Management, 23(4), 411-428. https://doi.org/10.1108/14777260910979308

Wong, C. A., \& Giallonardo, L. (2013). Authentic leadership and nurse-assessed adverse patient outcomes. Journal of Nursing Management, 21(5), 740-752. https://doi.org/10.1111/jonm.12075

\section{Copyright Disclaimer}

Copyright for this article is retained by the author(s), with first publication rights granted to the journal.

This is an open-access article distributed under the terms and conditions of the Creative Commons Attribution license (http://creativecommons.org/licenses/by/3.0/). 